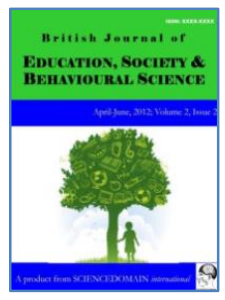

British Journal of Education, Society \& Behavioural Science

7(1): 25-41, 2015, Article no.BJESBS.2015.069 ISSN: 2278-0998

SCIENCEDOMAIN international

www.sciencedomain.org

\title{
Barriers and Enablers for Implementing Music in Australian Schools: The Perspective of Four Principals
}

\author{
Alexander Hew Dale Crooke ${ }^{1^{*}}$ and Katrina Skewes McFerran \\ ${ }^{1}$ Department of Music Therapy, Melbourne Conservatorium of Music, The University of Melbourne, \\ Victoria, 3010, Australia.
}

Authors' contributions

This work was carried out in collaboration between both authors. Author AHDC collected and transcribed some interviews, performed the qualitative analysis, and wrote the first draft of the manuscript. Author $K S M c F$ designed the study and facilitated access to the school leaders. Both authors contributed to the literature review, the refinement of ideas. Both authors read and approved the final manuscript.

Article Information

DOI: 10.9734/BJESBS/2015/16090

Editor(s):

(1) Satu Uusiautti, University of Lapland, Rovaniemi, Finland. (2) Shao-I Chiu, Taipei College of Maritime Technology of Center for General Education, Taiwan. Reviewers:

(1) Nancy Maynes, Nipissing University, Canada. (2) Milton Rosa, Centro de Educação Aberta e a Distância (CEAD), Universidade Federal de Ouro Preto (UFOP), Brazil. Complete Peer review History: http://www.sciencedomain.org/review-history.php?iid=822\&id=21\&aid=8075

Original Research Article

Received $6^{\text {th }}$ January 2015

Accepted $23^{\text {rd }}$ January 2015

Published $7^{\text {th }}$ February 2015

\section{ABSTRACT}

Aims: To explore and identify the barriers and enablers of music provision in Australian schools, as seen through the eyes of four Melbourne-based school principals, to inform policymakers and other school leadership teams.

Study Design: The study used an exploratory design.

Place and Duration of Study: Interviews were undertaken across multiple school sites in the greater-Melbourne area between June 2011 and April 2013 as part of a study conducted through the Melbourne Conservatorium of Music at The University of Melbourne.

Methodology: Four school principals were interviewed from diverse schools across the greaterMelbourne area, including primary, secondary, government, independent, mainstream, and special education schools. Interviews were transcribed verbatim, and analysed using a combined inductivedeductive approach to identify the barriers and enablers to music provision in schools reported by

${ }^{*}$ Corresponding author: E-mail: crookea@unimelb.edu.au, alexcrooke@westnet.com.au; 
principals. Themes arising from the data that related to either one of these factors were presented as the results.

Results: Analysis revealed eight main themes related to barriers: burden on schools, staff challenges, program relevance, convincing the school community, lack of appropriate resources, unsupportive leadership, sustaining a program, and competing models of education. Eleven enabling themes were identified, which included: existing level of arts, existing resources, school leadership, a tailored approach, external support, embedding music, staff support, involving students, convincing the school community, community partnerships, and working towards sustainability.

Conclusion: Findings support many barriers and enablers of school music identified in pervious international research, thus also confirming their presence and impact in the Australian context. Findings also provide insight into how the greater school community and the internal organisational cultures of a school can act simultaneously as both barriers and enablers of musical participation. Results also identify potential strategies for schools and policymakers aiming to support musical participation in schools.

Keywords: School music; policy; principals; school leaders; barriers; enablers.

\section{INTRODUCTION}

Advocates for arts in education include policymakers at international [1,2], national [3], and state levels [4], as well as music psychologists [5], music therapists [6], music educators [7] and members of the Australian arts community [8]. Despite such widespread support, Australian schools provide few opportunities for musical participation in government funded schools [9], especially when compared with countries such as the U.S. [10] and China [11]. This lack of access in our schools has largely been attributed to educational policies that, despite their written acknowledgement of the importance of music [4], continue to favour competitive schooling models that deprive most schools of the necessary support and resources to provide music [7].

As such, the provision of music has been left largely in the hands of schools themselves, meaning school leaders are charged with the decision as to whether they will devote their precious resources to music [12]. With little support from the government in this endeavour, and increasing pressure for schools to perform on standardised testing in core subjects [13], the decision to provide music is one that can require principals to negotiate a number of significant obstacles, and rely on creative resourcing strategies [14]. This paper presents the barriers, enabling factors, and strategies involved with the provision of music identified by four principals operating across diverse school contexts within the greater Melbourne area in Victoria. These perspectives are reported to provide insight into the struggles and strengths of principals dedicated to providing music for their students, while also illustrating where policy support may be directed if it should arise, and identifying practical strategies for principals should it not.

\subsection{Music in Schools}

Support for the role of music in educational contexts is based on a wealth of research literature that suggests musical participation can promote student development in a number of important areas. These have most commonly been described in terms of intrinsic and extrinsic benefits; with intrinsic benefits referring to the development of music based skills and competencies [15], as well as cultural awareness [16], and creative skills considered invaluable for participation in current knowledge-based economies [17]. Extrinsic benefits are described as increased cognitive [18] and academic development [19], as well as increased psychosocial wellbeing [20] and functioning [21].

Despite the recognition of these benefits in key policy documents at both national [3] and international levels [22], music is not mandated in Australian schools [23]. In practice, policy in this country continues to take a neo-liberal stance to education that favours competitive funding and reduced public expenditure on "non-essential" subjects [24] such as music. This has lead to inequality in the provision of music in Australian schools, with the most recent reports stating that only $23 \%$ of government schools provide opportunities for meaningful musical participation, as compared to $88 \%$ in the private sector [25]. This is concerning given developed Western countries such as the U.S. deliver music 
programs in $94 \%$ of elementary schools [10], and Asian countries such as China have been mandating music in the curriculum since the turn of the millennium [11]. In order to provide Australian students with similar opportunities to those being provided on the global stage, the issue of access needs be addressed.

\subsection{Barriers and Enablers}

While music is supported in Australian schools at a theoretical level - and suggested arts curriculums do exist [26] - little practical support is available. This means schools wanting to provide students with the numerous benefits afforded by musical participation are faced with a number of barriers. These include a significant lack of: musical skills and expertise among teaching staff; practical and financial resources; and available time to dedicate to musical activities [27]. Other barriers include access to staff professional development, and musical facilities [9]. While private schools are often able to acquire resource support from their more affluent parent communities, public-funded government schools are often required to rely on limited opportunities for community partnerships or philanthropic funding [12].

\subsection{The Role of School Leaders}

Recent research has highlighted the role school leaders play in enabling the provision of music in schools across the board [12,14]. A focus group undertaken during a symposium with nine Australian school leaders revealed that, while a lack of resources, infrastructure, and the continued dominance of literacy and numeracy in current education models continue to hamper efforts to provide music, a number of strategies are available to principals who are dedicated to this end [14]. These include creative strategies for acquiring financial support - including contributions from both the school community and charitable organisations - as well as the appropriation of community based partners and resources to augment infrastructure and skill deficiencies. The reported outcome of such strategies was a number of musical programs notable in their size and quality.

Perhaps the most significant enabling factor identified in relation to the school leaders attending the symposium was their commitment and dedication to the provision of music, and their willingness to find ways to overcome barriers. Sometimes this was most clearly exemplified in the preparedness of some leaders to mandate the musical involvement of students from an administration level. The benefit of such a stance was similarly illustrated through an investigation of a strings program in an innersuburban school in one of Melbourne's lower socioeconomic neighbourhoods [12]. Music facilitators engaged by the school noted how the success of the program in supporting the social and educational development of numerous atrisk students was enabled by the attitude of the principal. The principal's own musical background informed her commitment to giving music an equal standing to other educational activities and meant the benefits extended to the wider school community: "She will come in and say 'You just learn it like reading and maths.' She puts it on the same level and tells the kids that, and it means the interaction is always happening with the whole school community" [12].

These reports highlight the critical role school leaders have in the provision of music, and given the need for more music in Australian schools, suggests more research is needed to understand how they perceive the barriers and potential enablers of music in their schools. Such evidence is necessary not only to understand better the complex nexus between the desire for increased musical participation and the reality of running a school in today's policy climate, but also to inform policymakers and music program providers about how best to help schools negotiate these tensions.

\section{METHODS}

\subsection{Aim and Research Question}

This article further explores the potential barriers to and enablers of music provision in Australian schools. It does so from the point of view of four different school principals, each of who lead very different schools in the greater Melbourne area. Academic research has so far largely neglected the point of view of principals in this area. Researchers that have sought principal opinions have predominantly done so using surveys [28] and have been outside the Australian context [29]. By answering the research question: "What are the barriers and enablers of music in schools reported by principals?", this research aimed to address this gap. In doing so, it aimed to gain insight into the struggles of providing school music from the point of view of those responsible for balancing calls for increased musical 
participation against education policies which do not support it practically.

\subsection{Participants}

The four principals included in this analysis were from four very different schools that spanned the geography of the greater-Melbourne area. These included a government run Prep to Year 9 School in Melbourne's inner-western suburbs; a government run Primary School on the fringes of Melbourne's outer-eastern suburbs; a government run Prep to Year 12 school for children with autism in Melbourne's outernorthern suburbs; and a private Catholic all-girls secondary school in Melbourne's inner-eastern suburbs. Two principals were female, two were male, and each varied in age, the length of time they had been at their respective school, and the stage of their career.

Each principal had agreed for their school to participate in a project called Music Matters, undertaken by the National Music Therapy Research Unit, based at the University of Melbourne. The Music Matters project aimed to foster an understanding of the principles of musical engagement in schools (www.musicmattersinschools.com.au). It was delivered both as a series of in-school music programs facilitated by project staff, and as a consultancy service for schools wanting to start their own programs, or strengthen existing ones. Music Matters focused on finding ways to implement music programs that met the specific needs of schools, and drew on existing resources. Sometimes this took the form of more formal training in the use of music as a developmental or engagement tool. Other times it aimed to provide training in programs that did not require school staff to have any musical expertise, such as knowledge of music theory or proficiency in an instrument. This often meant focusing on activities that utilised existing or familiar resources and involved little training, such as music listening or lyrical composition.

\subsection{Data Collection}

Principals were interviewed at their schools at varying stages of their participation in the Music Matters project. Interviews ranged from one to two hours, and followed a semi-structured schedule, starting with questions such as "Can you tell me about your involvement in the Music Matters project". Interviews were originally intended to elicit general responses regarding their involvement in the project, and to explore the ways that school leaders conceived the potential of music participation for increasing connectedness and wellbeing. However, each principal took the opportunity to speak at length on a range of topics, including the barriers they had experienced to the provision of music in their schools (before and during involvement with Music Matters), and schools more generally. They also reported several potential enabling factors, or strategies for providing music in schools. As such, analysis of these interviews was identified as appropriate in order to capture and interpret these perspectives more completely.

With the permission of principals, interviews were recorded using digital voice recorders. They were then transcribed verbatim for analysis.

\subsection{Data Analysis}

Interview data were analysed using a combined deductive-inductive approach to qualitative analysis. The two categories, "barriers" and "enabling factors", were established deductively before data analysis began. This was done in order to create a framework for organising data in a way that could answer the research question. Using these deductive categories to guide analysis, transcripts were then analysed inductively, one by one, in order to identify any challenges or enabling factors regarding the provision of musical participation reported by principals. After each interview had been analysed, all quotes in which challenges were described were allocated to the "barriers" category, and integrated into a dedicated spreadsheet. A list of all challenges identified in interviews was then generated from this spreadsheet. These were analysed to identify recurring or significant themes, and quotes were attributed to them. The same process was repeated for the "enabling factors" category.

This inductive-deductive approach has been noted as appropriate when research aims to answer a specific pre-determined research question, whilst also placing value on uncovering unexpected knowledge on the topic that is voiced by participants [30]. This analysis method was considered appropriate because, while the primary goal was to consider themes related to the research question, it also aimed to provide a qualitative account of the principals' experience expressed through their own voices. 


\section{RESULTS AND DISCUSSION}

\subsection{Reported Challenges}

Principals noted a number of potential barriers to the provision of school music programs. These included challenges they had experienced themselves, as well factors noted as barriers for schools more generally. These related to challenges in both initiating a program, and sustaining or supporting a program once initiated. Analysis of these barriers resulted in the construction of eight main themes: burden on schools, staff challenges, program relevance, convincing the school community, lack of appropriate resources, unsupportive leadership, sustaining a program, and competing models of education.

\subsubsection{Burden on schools}

All four principals noted that they were already grappling with a significant number of ongoing workload issues that were not related to music, but which affected their capacity to provide music programs. Some went on to acknowledge the hesitation this caused about taking on an unfamiliar or new program. For example, principal 1 noted:

Initially when you get approached with these things, I'm always a little bit cautious or worried about, not the impact so much, but the workload that comes with it for the school, and who you delegate that workload to.

Principals acknowledged increased workloads are often passed on to staff, potentially overloading already stretched roles, leading to decreased staff capacity, and as principal 3 noted, poorly delivered music programs: "music became quite a chore [...] so they did it in a very tokenistic way". This concern supports previous literature which states the increased workload placed on schools by music programs can be a significant challenge to the quality of such programs $[27,29]$. This also illustrates the practical need for school leaders to balance a desire for music with existing school needs.

\subsubsection{Staff resistance}

Three of four principals reported significant staff resistance to music programs. The source of this resistance included a reaction to the increased workload noted above, resistance to or "fear" of something new, reluctance to give up time spent teaching "core" subjects, feeling "threatened" by external music professionals, and feeling "uncomfortable" due to their own self-perceived "deficits in music".

While staff resistance to programs has been identified in previous literature, in the most part, this has related to feelings of inadequacy stemming from a lack of expertise [27,31]. There have been little or no reports of staff feeling threatened by the introduction of skilled professionals, or the push from a teacher (rather than policy) level to focus on "core subject" material. This suggests sources of teacher resistance may be more complex than previously reported.

Also of interest was that staff resistance sometimes transcended, and even compromised, relationships between staff and school leaders. Principal 1 suggested teachers could potentially undermine a program if unhappy with it: "if it was just me [pushing the program] they might go, when it gets a bit hard, 'oh well, I might just let that fade way, it's not going quite how we thought it might, so I can let it die and no one will notice and I don't lose pay for it, it's not part of my official duties'". Principal 2 reported how pushing a program which was threatening an existing staff member had "probably affected my relationship with her, and I've grown up with her, l've worked with her for 20 odd years". This suggests that staff resistance to music programs cannot only affect the program, but also a principal's relationship with their staff.

\subsubsection{Lack of appropriate resources}

A significant barrier reported by principals was access to necessary resources. Principal 1 suggested "a resource threshold" was a problem for "any school", while principal 2 claimed this threshold was an obstacle to principal's uptake of programs: "selling it to the principals is difficult because of resources". Resourcing issues were discussed in relation to three main areas: staffing, facilities, and funding.

\subsubsection{Staffing}

When asked if they would hire dedicated music staff in future, principal 1 replied, "I won't be able to do that", citing a lack of funding as the reason. They also suggested resources had prevented them accessing musical staff in the past: "an instrumental music teacher wouldn't come here because the facilities were crap". This meant they had to "rely" on other staff that had "limited capacity" due to other roles. They also noted the 
potential problem of letting the responsibility for music "fall back on one person who either burns out or moves on, and everything collapses because that one person moved on", thus suggesting the need to involve multiple staff.

For principals 2 and 3 , a lack of sufficient training and relevant professional development (PD) were seen to compromise the success or maintenance of a program severely. For principal 3 , getting a program going with existing staff was problematic given "They just didn't have that skill set at that time to own and develop it themselves". Further, building those skills was problematic because they didn't have access to someone who could develop them: "the PD [professional development] wasn't focused on music because we didn't have someone with that skill set”.

Access to dedicated music staff has been reported as a serious challenge for music in Australian schools for the most part of a decade $[9,32]$, as has sufficient teacher expertise [33] and support for teacher PD opportunities $[7,9,34]$. While the results support these previous findings, they also highlight the need for ongoing staff support. Principal 3 noted that, even where initial PD was provided by an external professional, teachers "would only [facilitate musical activities in class] when she was there". This and comments from all other principals suggested that without ongoing support tailored to the needs of individual programs and teachers, the longevity of a music program was not guaranteed.

\subsubsection{Facilities}

A lack of appropriate facilities has also been reported as a barrier to school music in existing literature $[9,35,36]$. Principal 1 further highlighted the devastating impact deficiencies in this area can have on the maintenance of music in schools:

[...] this school underwent a rebuild. It used to have a very vibrant performing arts culture, even though it's a very small campus. When the rebuild occurred, all of the faculties were torn down and we were in makeshift facilities [...] the area of the curriculum that dropped almost to zero was the performing arts ' $\mathrm{COz}$ they no longer had a drama room or a music room [...] when I got here we moved into the new buildings and it was clear that that [culture] was almost dead.
This suggests insufficient facilities can not only prevent the provision of music, but also decimate an existing music program or culture. This principal also indicated the unique importance of appropriate facilities in supporting music when compared to other areas of the curriculum: "I can teach English to kids anywhere, but I can't teach music anywhere because the noise is going to impact on the people around me". They also explained how lack of a "quality" space could also impact staff: "they just didn't have a quality venue, and that impacted on the motivation of the staff". These reports illustrate the breadth of impact that poor facilities can have on school music.

\subsubsection{Funding}

All four principals recognised the role of funding in providing music programs, yet principals from mainstream government schools reported this challenge more explicitly. This included recognition of both the amount of funding that was necessary, and the difficulty in acquiring it. Principal 1 stated, "I know [Music Matters] had to twist some arms [to get] funding, and all of this, to get [the program] happening in the school", suggesting an acknowledgment not only of the role of funding, but also the effort and expertise required to acquire it.

Principal 2 made continuous reference to the challenge that funding would pose to the maintenance of their existing programs: "its funding $[\ldots]$ it's a monumental amount of money we got to raise"; "funding [our specialist music teacher] for the rest of her time is going to be difficult, it's going to mean another $\$ 30,000$, and there's no way that we can get that". Importantly, this second principal had an impressive track record of finding capital from both government and non-government sources, and yet still considered the challenge of securing ongoing funding for a specialist music teacher to be a significant hurdle.

These reports reinforce previous recognition of the paucity of available funding for school arts programs both in Australia [7,9,34] and internationally $[37,38]$. They also highlight the reality of what quality programs can cost in the current climate, and how, even for those who have experience in doing so, acquiring funding can be a daunting proposition. 


\subsubsection{Program relevance}

Principals argued that programs poorly matched to the interests or skillsets of the school community were unlikely to "take hold". Principal 1 articulated this in terms of student musical interests: "asking hip hoppers to become classical musicians [...] I don't know how it would be embraced". Principal 3 also suggested programs not matched to the needs of different class groups were problematic: "We needed to have different strategies for different class groups".

Principal 2 summed up the issue of program relevance at a school-wide level when describing the topic of re-creating programs across different schools:

Other schools can't just adapt our music program to their environment, they will have to make alterations [...] There's too much of this instant, almost instant coffee, just put the program in and it works. You've got to do a lot of training, and understanding, [it's also about] philosophy, understanding what they're on about, what direction it is. What are you really trying to achieve?

Principals felt strongly that it wasn't sufficient to roll-out a program that has worked in one school to a new context without carefully considering the purpose of a program, how it would meet the needs of the school, and whether staff were properly prepared to implement it: "Because what they would say is that 'music doesn't work', when it's the implementation of the program that's not working". These comments support previous research findings that implementing music programs ill suited to a school community can negatively impact their support and uptake by schools [39,40].

\subsubsection{Lack of support from school community}

Gaining support from the school community was identified as another potential challenge to the uptake of music programs. Principal 1 reported parents were sometimes unsupportive of musical activities, both from financial and cultural perspectives:

These kids in this community [...] their parents won't necessarily be able to afford guitar lessons or drumming lessons or dance lessons; they won't necessarily engage with a boy, for example, who's a singer, their background might be that you should be kicking the footy, not singing.

This quote implied parents were neither in a financial position to support music programs, nor necessarily prepared to support their child's involvement if they were. An experience regarding a singing program provided to students free of charge recounted by principal 2 supports the later:

I had five parents come to me when we mandated that every child had to be part of the singing program, [they] said "my child doesn't want to do singing" [...] I didn't expect that.

The notion that family attitudes towards music may impede support for school music programs has not been widely reported. It also contradicts recent government reports that family and community support for the role of the Arts in education is $90 \%$ and above in developed countries such as Australia [8] and the U.S. [41]. This suggests a level of resistance within the wider school community previously unidentified in the literature.

Principal 3 also reported difficulty in communicating benefits in a way that solicited support for the program from teaching staff: "It was hard for me to impart how important music was to teach every day, and I knew how important it was, but didn't know how to convince people." Comments in this theme both highlight the challenge that resistance from the school community can pose, but also that school leaders may be under-resourced to address it.

\subsubsection{Competing models of education}

Principals reported some approaches to education undermined the provision of music programs. This was most strongly articulated by principal 2, who suggested that the government "dropping music out of the core curriculum" had severely affected the place of music in schools. Further, the policy focus on "high-stakes testing" models that dominate Australian schooling and allocate funding based on "data driven results", means both principals and teachers can be reluctant to undertake any activity that will divert time or resources away from achieving results in "core subjects".

The impact of education models privileging highstakes testing has been widely recognised as affecting arts education at an international level $[7,38,42-44]$. This raft of evidence, however, 
focuses on the top-down effect of these policies, where principals and teachers are restricted in what they can implement within a school or classroom by policy funding and or regulations. While this top-down effect was indeed reported as a barrier to the provision of music programs by principals interviewed here, what appeared more significant was the appropriation of these policies and education models by the teachers themselves, as well as other leadership staff. Principals often reported that, even when they were willing to circumvent restrictive policies or regulations to provide music programs, staff commitment to policy-driven models of education often presented a significant obstacle. For example, both principals 1 and 2 reported some teachers were resistant to any program that either; took time away from "core subjects"; potentially prevented them from getting results necessary to compete in school or class rankings; or were not perceived as sufficiently academic in focus. This reveals the full weight of existing policies and education models, suggesting that in some cases they may be embedded within the philosophical perspectives of staff. This implies both top-down and bottomup strategies are needed to combat the barriers such education models pose to music provision.

\subsubsection{Unsupportive leadership}

Unsupportive leadership was also reported as a potential inhibiter to the uptake of school music programs. Principal 4 suggested leadership that takes a narrow view of schooling can limit the support and implementation of music (and other) programs that have benefits not strictly aligned with traditional academic subjects. Similarly, principal 2 suggested principals often focus on "ministry" driven models of education and are unwilling to consider the possibilities that music programs could have for their school community. This principal challenged the "philosophy" of such school leaders, and the impact this had on their willingness to think about what is best for their students:

What I would challenge principals on is really articulating what they are on about [with] education, and what they firmly believe in, and it's not what the ministry is pushing: they have to hold the ground on what they truly believe their philosophy of education is.

This idea that school leaders can present a barrier to the implementation of music programs, either by being unsupportive, or unwilling to consider the value of musical participation if it is not mandated or recommended by policy, contradicts existing evidence in this area. While limited, existing reports depict principals as taking on enabling roles only, and provide little to no discussion of their potential in hindering the adoption or facilitation of music programs [28,29]. Both principal 2 and 4 emphasised that if music is not supported at a leadership level, the chances a school will participate in musical activities are limited, thus highlighting the critical importance of leadership support.

\subsubsection{Sustaining a program}

All four principals expressed clear concerns about the sustainability of music programs (see Table 1). While comments on this topic (and many of those below) were predominantly related to programs provided by Music Matters, comments also serve to communicate the experience of engaging in music programs more generally. Specifically, comments in this section illustrate the importance of addressing sustainability when delivering any program. While the need for sustainability is evident within existing literature $[9,45]$, responses presented here provide some insight into the nature of this concern and the limited value of non-continuing programs or program support.

The most common anxiety was how to sustain a program that had been set up and run with the external assistance once support was removed. This referred to staffing positions supplied by external organizations, maintaining the skills and expertise provided by organizations within their own team, and accessing the funds necessary to continue music programs more generally. This highlights the potential peril of short-term consultancy approaches for supporting music in schools.

\subsection{Reported Enablers}

Despite the plethora of challenges reported by principals, a greater number of key enabling factors were described. These included characteristics identified across schools that appeared to support the uptake and sustenance of programs, as well as strategies for supporting music in schools over time. These enabling factors were categorized into 11 themes: existing level of arts, existing resources, school leadership, a tailored approach, external support, embedding music, staff support, involving students, convincing the school community, community partnerships, and working towards sustainability. 


\subsubsection{Existing level of the arts}

All four principals reported their schools had placed significant focus on the arts prior to their engagement with the Music Matters program. This focus invariably involved recognition for the potential link between the arts and student wellbeing. Principal 4 stated "We are a school that is very strong in the arts area, so music's always had a very high profile" and "we're in a fortunate position that there is a great respect for the arts and what the arts can contribute [to] wellbeing". Principal 1 claimed "we've always, through our welfare programs, done things involving drumming, singing, dancing, as a way of bringing groups of kids together that might have a common issue, and kind of work their way through it".

Each principal also indicated that their initial decision to engage with the Music Matters program was motivated by this recognition for the benefits of arts activities, and was seen as a way to strengthen or "bolster" the level of the arts in their school. These comments suggested that an existing presence of arts or music activities in a school might help provide conditions that promote further engagement in music programs. These results are partly supported by research in the U.S. [28], which suggests principals who already have music in their schools may be more likely to pursue further engagement.

\subsubsection{Existing resources}

The presence of appropriate resources was also seen to promote the place of music in schools. Principal 4 described this in terms of having the "support systems to make [a program] as successful as possible", both in relation to staff support, and practical resources. Principal 2 and 3 further reported on the value of having systems in place for the ongoing support of staff that are expected to deliver music programs. This supports previous findings that having appropriate staff resources and support was seen by principals as the "single most important factor in enabling [the] success" [29] of music programs.

Principals 1 and 2 both also expressed this in terms of having appropriate facilities in the school, and the level of "enthusiasm", "pride", "ownership", and "respect" they can foster for a music program among students and staff. While the negative impact of insufficient facilities has been reported $[9,35,36]$, these results also highlight the potential enabling qualities of such resources.

\subsubsection{School leadership}

The characteristics of the school leaders themselves were reported to be one of the most important enablers for the adoption of music programs, their success, and their maintenance. In terms of adopting a program, all principals reported there needed to be a level of understanding for the potential of music programs, including their ability to address student needs. This included recognition of how a program could feed into or support pre-existing school goals, such as bolstering the roles of arts or "up skilling staff", and recognition of the role that music plays in the lives of young people. Underlying this recognition was the "philosophy of education" held by school leaders, which was seen to value "the whole child", a "holistic approach" to education, or as principal 4 put it, "a policy of understanding".

Having a certain attitude, such as openness to the "opportunities" of music, was also noted as important. As principal 4 reported, this included the need to "have a strong commitment to being willing to have a go", which sometimes meant being "prepared to take that risk". For both principal 2 and 4 , this attitude also included the ability to recognise and act on "research that exists both in schools and [outside schools]".

Some principals also reported a tenacious attitude to their support of music. Principal 2 declared, "I was very much focused on making the music successful, and integrated into the whole curriculum", which was something they mandated. Similarly, principal 1 noted that "I had to get intimately involved, pushing, shoving, making things happen" to support music in the school. Such comments describe the commitment of leaders to support music, even going so far as to make participation for students and teachers compulsory. While often met with the resistance noted earlier in the article, as principal 4 reported, this tactic was seen as effective: "I think that the leadership team has to be explicit with it, [...] what that does then is not only give a license for people to believe that, but in fact gives a mandate for people to work like that".

However, principals also reported that mandating participation alone was insufficient. Ongoing support from school leaders was seen as 
necessary, which often meant "involving" staff and students in decision making, and empowering them to take ownership of programs.

When describing their collaboration with Music Matters, principal 3 noted leadership support was also necessary for external providers: "she [...] had a problem, and I advised her that she needed to go in more concretely [with staff]". By "go[ing] in more concretely" principal 3 is explaining how she had advised the external music practitioner to be more direct with the regular class teachers she was working with, and the need to use practical examples when explaining program activities and processes.

Other characteristics school leaders reported as crucial were "being practical" and creative in terms of "finding resources" or ways to integrate music into an already crowded school day. Principal 1 noted this included "being strategic about where [a program is] placed", while principal 4 suggested, "you've got to work with the reality in the [school] setting [...] you've got to prioritise". For principal 2, being strategic, creative and persistent was necessary to find funding: "Because I have the strong view that, if you want to do something, you'll find resources or ways of doing it [but to] get that resource, we've got to [...] almost dream something up".

This evidence expands on recent research which has identified the critical role support from school leaders, and their convictions regarding the benefits of music, can play in enabling the provision of music in schools [12]. It also reinforces reports that the dedication and creativity employed by principals in finding the means to support music programs can sometimes overcome resourcing issues [14].

\subsubsection{A tailored approach}

Three principals reported a program "individually tailored" to meet the needs of a school was more likely to be successful. For principal 2, this meant making "alterations" to make sure it matched the "environment" and resources within a school. Principal 3 described this as the need to "Break it down to [...] different developmental levels" in order to provide "different strategies for different class groups and different students".

Principal 1 explained how the timing and the adaptability of the Music Matters program "allowed us to get some things happening that we wanted [but] would have taken another [...] two years to get it to where it is now". This included re-invigorating the presence of arts and "getting some teachers [to] look at what they're doing and how they could do it differently" in terms of teaching methods and increasing student participation in music and school more generally. This synchrony was largely credited to the initial consultation process with the Music Matters team:

Table 1. Theme: Sustaining a program

\begin{tabular}{|c|c|}
\hline Source & Quote \\
\hline \multirow[t]{4}{*}{ Principal 1} & $\begin{array}{l}\text { But the key here is the sustainability when [Music Matters] finishes, that these things } \\
\text { continue. That's a worry for me }\end{array}$ \\
\hline & $\begin{array}{l}{[\ldots] \text { we need to sit and work out how that is done }[\ldots] \text { so that next year there is still these }} \\
\text { things going on }\end{array}$ \\
\hline & $\begin{array}{l}{[\ldots] \text { build in some things where these just become part of daily life here in the campus, }} \\
\text { rather than it happen because [the Music Matters] team come in, and that will be the } \\
\text { challenge I think }\end{array}$ \\
\hline & $\begin{array}{l}{[\ldots] \text { which happens lots of times in schools, even the government will do it, they'll give }} \\
\text { half a million dollars for the programs and the program runs beautifully and then they go } \\
\text { "you no longer need the half-million dollars" and then the program collapses. I see that a } \\
\text { lot }\end{array}$ \\
\hline \multirow[t]{2}{*}{ Principal 2} & $\begin{array}{l}\text { The other challenge will be how we continue to resource these activities, as you know } \\
\text { we've got one more term with the [Music Matters program] and then we'll have to look at } \\
\text { where we will go from there }\end{array}$ \\
\hline & {$[\ldots]$ and again it's funding that to the next stage } \\
\hline Principal 3 & $\begin{array}{l}\text { I don't think we're ready yet to go with what we've learned [from the Music Matters team]. } \\
\text { We need two or three more years to reinforce or build on our skills. Two or three days a } \\
\text { week, working in this way, in classrooms with teachers }\end{array}$ \\
\hline Principal 4 & $\begin{array}{l}{[\ldots] \text { what }[\text { Music Matters] provided }[\ldots] \text { was something that doesn't exist within a school }} \\
\text { on its own }[\ldots] \text { It doesn't continue as well as if she was there to do it }\end{array}$ \\
\hline
\end{tabular}


[...] when I sat down with [Music Matters representative] and we went through what she thought she could offer and what we would need to give in return with that, it seemed to me to have arrived with the right kind of ideas at the moment when we were willing to inject something into that part of our school.

Principal 1 also described how the Music Matters program was able to capitalise on the resources within the school community, to support what they considered unengaged or vulnerable students:

A good example would be [...] the Arabic community, they are very much [...] into the drumming, the islander kids are very much into the hip hop. [The program] allows them to have a positive way of presenting their culture in this community through music.

This quote shows the wide-ranging potential of tailoring programs in ways that not only meet the needs of school, but also tap into both existing physical and cultural resources to do so. Here principal 1 describes how a music program that drew upon the cultural backgrounds of disadvantaged students not only engaged these students, but also enabled them to interact with the school in a positive way; both as students, and as members of their own cultural communities.

This affordance was attributed to the willingness of the Music Matters facilitators to design the program to match the needs of the student population. These findings support existing claims for the need to tailor music programs to the cultural [46] and other needs of students [12], as well as school communities more generally [47].

\subsubsection{External support}

All four principals explained how the support and expertise of an external team can greatly contribute to the successful implementation of a music program. While again comments here refer predominately to external support received during the Music Matters program, these reports signify the potential benefit of obtaining any form of specialised support from outside the school. For principal 1, the fact the Music Matters team undertook "a lot of the workload" meant there were fewer burdens on staff. Their presence also meant staff was "enthused" and motivated to "commit" to the program.
Similarly, principal 3 suggested a Music Matters facilitator "initially setting up all the sessions and bringing the resources in", as well as providing opportunities for PD, gave staff the "confidence" to integrate music into their daily classes in a more meaningful way. They also acknowledged the facilitator "changed the beliefs [and] opened the minds of teachers", crediting this to their expertise: "Her manner helped too: how she did it was very powerful. She did it very subtly."

Principal 4 stated the Music Matters facilitator at their school "had the capacity to come in and influence what was happening throughout the school across a variety of programs at various year levels". This was considered valuable because it helped "embed a music therapy philosophy across the school program", instilling recognition for the wellbeing benefits of music.

All principals also mentioned more practical support provided by the team. This was described as having an "extra set of hands", the provision of music instruments, program plans, or learning materials.

These principals' recognition of the specific skills and enthusiasm provided by specialist music staff when delivering music programs is again supported by existing evidence [29]. However, this previous evidence refers to specifically to the recruitment of specialists onto permanent staffing rosters, leaving the benefits of externally provided expertise less identified.

\subsubsection{Embedding music}

Three principals noted embedding music into the existing school structure was a valuable strategy for accommodating and sustaining music programs. At a philosophical level, principal 4 and 2 defined this in terms of embedding the significance of music within the values and culture of the school.

Embedding music activities within "existing programs" was described as a more practical strategy, especially in cases where resources to support a music program "in isolation" were reported as scarce. For principal 2, this predominantly meant embedding within the "curriculum", but also included performances at school events such as assemblies, as well as "piggybacking" on specialised literacy and numeracy programs. Principal 1 also talked about embedding within the curriculum, but suggested it could equally "sit in the welfare program". They also indicated the importance of 
being "strategic" and consulting with teachers to find places where it suited them to embed music in the curriculum. They also mentioned the potential of involving the Student Representative Council (SRC) in the facilitation of music programs, in that it could be embedded within their role, or duties, each year: "or [perhaps] the SRC will just take that on every year and that'll be one of the things they do".

Importantly, this enabling factor has been largely unrepresented in existing literature. That this was such an important approach for these principals suggests it may provide a useful strategy for other schools and school leaders.

\subsubsection{Staff support}

All principals saw generating staff enthusiasm about the potential for using music as a critical factor to the uptake and maintenance of a music program of any kind. For principal 4, this meant building a "heightened awareness" regarding the holistic benefits of music, and creating an expectation among staff that music be used to this end.

For principals 1,2, and 3, "finding the right way to be supportive" to foster a sense of "confidence", acceptance and program "ownership" among staff was considered invaluable. All three described this in terms of providing practical resources so staff didn't become overwhelmed; external support such as PD; external providers to help them "carry the load"; and involving them in consultation. Principal 2 also suggested they had to "manipulate [a music] program to fit into a timetable where [teachers] felt it wasn't affecting the time that they had [for other] subjects".

Principal 2 also advocated the value of taking on a program that "doesn't require teachers to have musical knowledge" to increase receptiveness. This refers to the implementation of programs that do not require teachers to have specific training as a musician, or as a music teacher, such as song-sharing or simple lyrical composition. While such activities often required some initial guidance for staff, they employed existing, familiar, and accessible resources (for example, rewriting lyrics to popular songs using their instrumental versions available through www.youtube.com), in an effort not to expose teachers to any perceived discomfiture involved in directing musical instruction, or performing music themselves.
These responses indicate the importance of taking time to facilitate staff engagement, or buyin, to a program - particularly when staff members are asked to deliver them. They also suggest there are several ways to achieve this, including designing programs that are not perceived as an imposition in the time they require, or intimidating in the skills needed to deliver them. Providing initial and ongoing staff support also appears here as a key factor.

Interestingly, the need to foster staff support and engagement is not reported widely in the literature. However, the fact all principals reported this, suggests it is an important enabler of school music programs.

\subsubsection{Convincing the school community}

All principals also identified support from the wider school community as an important enabler, and reported several strategies for developing this support. This included the perceived need "to educate [teachers,] the wider community, and our parents" in order to "build respect" and "understanding" for the benefits of musical participation. Principals 2, 3, and 4 saw access to research clearly demonstrating these benefits as pivotal in this process. Principal 4 noted, however, such research needed to accessible:

It's all very well to talk about general theory, but really what people want to know is "how will this impact on the day-to-day work?" And I think that people [need] to break down the information to that level and say, "This is the difference that it can make in your classroom."

This principal also claimed the "need to be very practical in [getting] the message out about how it can make a difference and [...] be useful", and "taking a bit of a marketing notion" to do so: "you don't just put your message out in one form". Potential "marketing" approaches described for teachers included PD. In-school and public performances were also considered useful for presenting tangible music outcomes to students, parents, staff, and the community. Principal 1 suggested:

[...] doing a performance thing, it's easier to see [the outcomes], there is a performance at the end and it's either good, bad or indifferent, and the kids either come to it really willingly or enthusiastically or they haven't, so you're able to place a judgment on it. 
Principal 1 also advocated the benefits of getting "quick successes" through music programs when garnering support from staff:

When success is wrestled then sometimes staff will get it and then say that's enough. But when they're getting some quick wins and they can see the value very quickly, l've noticed the enthusiasm of staff around it increase with it.

While some authors have noted that performances should be used with caution when working with students [12, 48], this evidence shows there is a clear need to provide principals with effective ways to communicate the benefits of music to the community. This need has been identified by previous authors [7,14], as have the benefits of performances within music therapy more broadly [49].

\subsubsection{Community partnerships}

As demonstrated in Table 2, three principals considered community partnerships highly beneficial. Benefits ranged from the ability to connect with and access resources and skills from within their local community, to engaging with community organisations and events in order to provide a forum for undertaking musical activities. The value of strong partnerships among schools and external artists [35], community groups [33], and community organisations [7] are recognised in the literature. These results support this recognition, and suggest that in a time of budgetary cuts in Australia [50] and across the world [38], partnering with external non-government organisations may be an important strategy for enabling school music.

As well as the musical opportunities these connections afforded, all three principals also talked about the benefits of the connection process in itself, particularly with universities, both in the exposure this provided students, as well as the opportunities it provided for schools more generally. In many cases, music was seen as a way to initiate and foster these community connections, which in some cases were seen to feed back into the strength of a school's music program, and the school more broadly. This suggests music-based community connections may have more than musical benefits.

\subsubsection{Working towards sustainability}

Working towards and promoting sustainability was universally identified as one of the key enablers of school music programs. While each of the "enabling themes" reported above were seen as key to the sustainability of school music programs (particularly the idea of embedding music in existing school structures), principals noted other factors they believed would promote sustainability, but which did not fit into any of the above themes. Importantly, while sustainability has been noted as an important theme in the literature $[9,45]$, there is little discussion of how this can be approached. The strategies reported here go someway to informing this gap.

Both principal 2 and 4 placed strong emphasis on the potential for greater partnerships between schools and universities, particularly in the form of student placements from university music therapy programs. They saw this as a symbiotic relationship in which university students could gain experience in education contexts, and schools could benefit from the input of high-level skills, knowledge and training.

While all four principals clearly indicated that longer contact with and support from the university and the Music Matters program would have been preferred, there was recognition from principals 1,2 , and 4 that schools also need to take ownership and responsibility for the music provision themselves. As principal 4 noted, this required making the most of what was offered: "[they were] able to pass on some of that expertise that can yet continue. It doesn't continue as well as if [they were] there to do it, but it's better than nothing at all". Similarly, principal 2 suggested that if programs are of sufficient quality, and schools have been serious in their engagement, programs can be sustained:

[What's] disappointing is that we can't continue involvement [with Music Matters], but again, I guess I take the view that if the program has been successful and the involvement of your group has been successful, then the program will generate its own inertia to go on. Because if it doesn't then it means we've missed the boat somewhere.

On a final note, principal 2 also suggested the need to look at the bigger picture, and advocated the need to take a long-term approach to securing the place of music in schools: 
Table 2. Theme: Community partnerships

\begin{tabular}{|c|c|}
\hline Source & Quote \\
\hline \multirow[t]{5}{*}{ Principal 1} & $\begin{array}{l}\text { [...] using funding from student youth services at the local council she would get } \\
\text { people in to do a drumming program or to do a dancing program with the kids }\end{array}$ \\
\hline & {$[\ldots]$ it's been good to interact with an outside group } \\
\hline & $\begin{array}{l}{[\ldots] \text { we'll take this into the community }[\ldots] \text { and we're talking to the elderly citizens }} \\
\text { about bringing their choir up and doing a joint song }\end{array}$ \\
\hline & [...] and also [Music Matters] being involved with the [school] is kind of good \\
\hline & $\begin{array}{l}{[\ldots] \text { for the kids here to see that there is people from the university who are coming in }} \\
\text { to work with them is a positive for the kids }\end{array}$ \\
\hline \multirow[t]{3}{*}{ Principal 2} & $\begin{array}{l}\text { [On] ANZAC (Australian and New Zealand Army Corps) day [...] our children [are] } \\
\text { involved with the ceremony. RSL (Returned Services League) now expect that that's } \\
\text { part of the ritual [to] walk or march with them [and] have a key feature of the national } \\
\text { anthem and singing a new song every year }\end{array}$ \\
\hline & $\begin{array}{l}{[\ldots] \text { the Governor }[\ldots] \text { and the Premier came }[\ldots] \text { the students had to actually perform }} \\
\text { in front of these people, and they embraced that, and that lifted their innovation and } \\
\text { also their performances, and probably gave them what was important about music }\end{array}$ \\
\hline & $\begin{array}{l}{[\ldots] \text { we've got ex students who help us with the songs in terms of practice, but also }} \\
\text { the technical side, and parents as well }\end{array}$ \\
\hline Principal 4 & $\begin{array}{l}{[\ldots . .] \text { the capacity to create partnerships in our community of using people like [the }} \\
\text { Music Matters representative] as a music therapist, and even the work we do with our } \\
\text { education consultant, and the work we do with [multiple universities], is recognising } \\
\text { other people's expertise as well [...] working together }\end{array}$ \\
\hline
\end{tabular}

[...] whereas in the younger days you'd be hellbent on achieving the change quickly, I'm much more measured these days. The change will happen over a period of time, it's planting those seeds in people about why music is important in education.

\section{CONCLUSION}

The gap between calls for quality school-based musical participation and the amount of participation that occurs in Australian schools is significant. The perpetuation of this gap is widely reported and underpinned by systemic inequalities in the provision of music, as well as a lack of resources needed for schools to implement quality music programs. This article presents a qualitative account of the ongoing barriers to school music provision as experienced by principals in Australian schools. While reported barriers such as access to financial and staffing resources support existing literature, these principals indicate there are a number of more ingrained barriers to music programs in Australian schools, including resistance from different levels of the school community. They also highlight the potential pitfalls of implementing standardised programs unsuited to the needs of individual schools. Importantly, these principals also report an even greater number of enabling factors and strategies for the provision of school music programs. While factors such as funding and staff support and training have been reported previously, a number of further approaches are identified which may also be important in helping to overcome barriers. These include the conviction and creativity of school leaders, empowering the school community to take ownership of music activities, taking advantage of accessible resources, and embedding music within existing school structures. This article goes some way to filling the gap in the literature regarding the lived experiences of providing music in schools, and highlights both important areas for future policy support, and strategies that can be employed in order to promote music in an era of competitive schooling.

\section{ETHICAL APPROVAL}

Ethics approval was sought and granted from the Human Research Ethics Committee at the University of Melbourne, as well as the Department of Education and Early Childhood Development. All principals provided consent to participate and have their views distributed for research purposes.

\section{COMPETING INTERESTS}

Authors have declared that no competing interests exist. 


\section{REFERENCES}

1. UNESCO. International appeal for the Promotion of the Arts in education. General UNESCO conference; 1999. November 3; Paris: UNESCO.

2. UNESCO. Building creative capacities for the $21^{\text {st }}$ century. World Conference on Arts Education; 2006; Lisbon, Portugal.

3. MCEETYA, CMC. National Education and the Arts Statement. Canberra: Ministerial Council on Education Employment Training and Youth Affairs, and Cultural Ministers Council; 2007.

4. Parliament of Victoria. Inquiry into the extent, benefits and potential of music education in Victorian schools. Education and Training Committee: Victorian Government Printer; 2013. 29 May 2013. Parliamentary paper No. 277.

5. Gill A, Rickard N. Non-musical benefits of school-based music education and training. In: Rickard NS, KM, editors. Lifelong engagement with music: Benefits for mental health and well-being. Hauppauge NY, United States: Nova Science Publishers, Inc. 2012;57-72.

6. McFerran KS, Rickson D. Community music therapy in schools: Realigning with the needs of contemporary students, staff and systems. Int $\mathrm{J}$ Community Music. 2014;7(1):75-92.

7. Ewing R. The Arts and Australian Education: Realising potential. Camberwell, Victoria: Australian Council for Educational Research; 2010.

8. ACA. More than bums on seats: Australian participation in the arts. Sydney: Australian Council for the Arts; 2010.

9. Australian Government, DEST. National Review of School Music Education: Augmenting the diminished. Canberra, Australia: Department of Education, Science and Training, Australian Government; 2005.

10. Parsad B, Spiegelman M. Arts Education in Public Elementary and Secondary Schools: 1999-2000 and 2009-10. Washington, DC: National Center for Education Statistics, Institute of Education Sciences, U.S. Department of Education; 2012.

11. Ministry of Education, China. Full-time compulsory music curriculum standards. Beijing, China; 2001.
12. McFerran KS, Crooke AHD. Enabling Tailored Music Programs in Elementary Schools: An Australian Exemplar. J Educ Train Stud. 2014;2(4):138-47.

13. Lingard B. Policy borrowing, policy learning: Testing times in Australian schooling. Crit Stud Educ 2010;51(2):12947.

14. McFerran KS. You're the voice: Principals views about music in schools. Australia: The University of Melbourne; 2011.

15. Taylor C. Both Sides, Now: Balancing the Extrinsic and Intrinsic Benefits of Music in Music Advocacy. Can Music Educ / Musicien Educ Can. 2008;49(3):36-8.

16. Jones PM. Developing social capital: a role for music education and community music in fostering civic engagement and intercultural understanding. Int $\mathrm{J}$ Community Music. 2010;3(2):291-302.

17. Lebler D. Student-as-master? Reflections on a learning innovation in popular music pedagogy. Int J Music Educ 2007; 25(3):205-21.

18. Roden I, Kreutz G, Bongard S. Effects of a school-based instrumental music program on verbal and visual memory in primary school children: a longitudinal study. Front Psychol. 2012;3:572.

19. Biasutti M, Concina E. Music educaton and transfer of learning. J Commun Res 2013;5(3):397-413.

20. McFerran KS. Music Therapy with Bereaved Youth: Expressing Grief and Feeling Better. Prev Res. 2011;18(3):1720.

21. Baker $F$, Jones $C$. Holding a steady beat: The effects of a music therapy program on stabilising behaviours of newly arrived refugee students. $\mathrm{Br} \mathrm{J}$ Music Ther 2005; 19(2):67-74.

22. Bahri S. Educating Through Art in Secondary Education. UNESCO Expert Panel Meeting, Education Through Art Proceedings; 2006; France: UNESCO.

23. ACARA. Shape of the Australian Curriculum: The Arts. Sydney, NSW: Australian Curriculum, Assessment and Reporting Authority; 2011.

24. Russell-Bowie D. An ode to joy... or the sounds of silence? An exploration of arts education policy in Australian primary schools. Arts Educ Policy Rev. 2011;112(4):163-73. 
25. Stevens R. National report on trends in school music education provision in Australia. Melbourne: Music Council of Australia; 2003.

26. VCAA. Progression points examples for AusVELS The Arts - Music Level 8-10. In: Victorian Curriculum and Assessment Authority SGoV, editor.: Victorian Curriculum and Assessment Authority, State Government of Victoria; 2012.

27. Russell-Bowie D. What me? Teach music to my primary class? Challenges to teaching music in primary schools in five countries. Music Educ Res. 2009;11(1):2336.

28. Abril CR, Gault BM. The State of Music in Secondary Schools The Principal's Perspective. J Res Music Educ 2008; 56(1):68-81.

29. Lamont A, Hargreaves DJ, Marshall NA, Tarrant M. Young people's music in and out of school. $\mathrm{Br} \mathrm{J}$ Music Educ 2003;20(03):229-41.

30. Fereday J, Muir-Cochrane E. Demonstrating rigor using thematic analysis: A hybrid approach of inductive and deductive coding and theme development. Int J Qual Methods 2008;5(1):80-92.

31. Hennessey S. Overcoming the red feeling: The development of confidence to teach music in primary school among student teachers. J Music Educ 2000;17(2):18396.

32. Heinrich J. The provision of classroom music programs to regional Victorian primary schools. Aust J Music Educ 2012(2):45-58.

33. Bamford A. The wow factor: Global research compendium on the impact of the arts in education. Berlin: Waxmann Verlag; 2006.

34. Davis D. First we see: The national review of visual arts education. Sydney: Science and Training Department of Education, The Australian Council for the Arts; 2008.

35. Mills J. State of the Arts Lecture. Presented by the Wheeler Centre in partnership with the Harold Mitchell Foundation and the National Gallery of Victoria. August 3; National Gallery of Victoria, Melbourne; 2010.

36. Schneider M. Linking School Facility Conditions to Teacher Satisfaction and
Success. ERIC document ED480552; 2003.

37. Abril CR, Gault BM. Perspectives on the Music Program: Opening Doors to the School Community. Music Educ J. 2007;93(5):32-7.

38. West C. Teaching Music in an Era of HighStakes Testing and Budget Reductions. Arts Educ Policy Rev. 2012;113(2):75-9.

39. Grimmett H, Rickard NS, Gill A, Murphy F. The Perilous Path from Proposal to Practice: A Qualitative Program Evaluation of a Regional Music Program. Aust J Music Educ. 2010(2):52-65.

40. Murphy F, Rickard N, Gill A, Grimmett H. Informing new string programmes: Lessons learned from an Australian experience. $\mathrm{Br} \mathrm{J}$ Music Educ. 2011;28(03):285-300.

41. New Harris poll reveals that 93 percent of Americans believe that the arts are vital to providing a well-rounded education [database on the Internet]; 2005.

42. Available:http://www.americansforthearts.o rg.

43. Robinson K. All our futures: Creativity, culture and education. London: National Advisory Committee on Creative and Cultural Education; 1999.

44. Sharp C, Le Metais J. Arts and cultural education at school in Europe. European Commission; 2000.

45. Taggart G, Whitby K, Sharp C. Curriculum progression in the Arts: An international study. Slough, UK: National Foundation for Educational Research; 2004.

46. Rogers L, Hallam S, Creech A, Preti C. Learning about what constitutes effective training from a pilot programme to improve music education in primary schools. Music Educ Res. 2008;10(4):485-97.

47. Doyle JL. Cultural Relevance in Urban Music Education: A Synthesis of the Literature. Update: Appl Res Music Educ. 2014;32(2):44-51.

48. Crooke AHD, McFerran KS. Recommendations for the investigation and delivery of music programs aimed at achieving psychosocial wellbeing benefits in mainstream schools. Aust J Music Educ. 2015;1:27-49.

49. McFerran KS. Adolescents, Music and Music Therapy. London. UK: Jessica Kingsley Publishing; 2010. 
50. O'Grady L, McFerran KS. The use of performances in music therapy practice in Australia: A qualitative study. $\mathrm{Br} \mathrm{J}$ Music Ther. 2012;26(1):24-38.
51. Kirby t. Health and science suffer major cuts in australia's budget. Lancet. 2014;383(9932):1874-6.

(c) 2015 Crooke and McFerran; This is an Open Access article distributed under the terms of the Creative Commons Attribution License (http://creativecommons.org/licenses/by/4.0), which permits unrestricted use, distribution, and reproduction in any medium, provided the original work is properly cited.

Peer-review history:

The peer review history for this paper can be accessed here:

http://www.sciencedomain.org/review-history.php?iid=822\&id=21\&aid=8075 


\section{University Library}

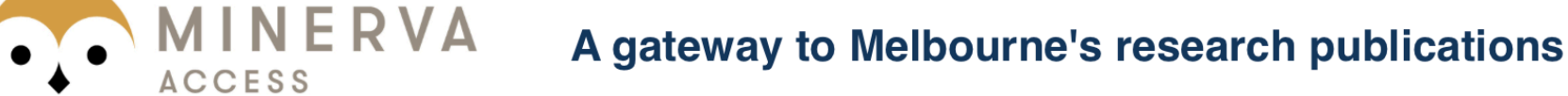

Minerva Access is the Institutional Repository of The University of Melbourne

Author/s:

Crooke, A;McFerran, $\mathrm{K}$

Title:

Barriers and Enablers for Implementing Music in Australian Schools: The Perspective of Four Principals

Date:

2015-01-10

Citation:

Crooke, A. \& McFerran, K. (2015). Barriers and Enablers for Implementing Music in Australian Schools: The Perspective of Four Principals. British Journal of Education, Society \&amp; Behavioural Science, 7 (1), pp.25-41. https://doi.org/10.9734/bjesbs/2015/16090.

Persistent Link:

http://hdl.handle.net/11343/58214 